\title{
Brazilin exerts protective effects against renal ischemia-reperfusion injury by inhibiting the NF-кB signaling pathway
}

\author{
YANYAN JIA $^{1^{*}}$, JINYI ZHAO ${ }^{2 *}$, MEIYOU LIU ${ }^{2 *}$, BINGLING LI $^{1}$, \\ YING SONG ${ }^{2}$, YUWEN $\mathrm{LI}^{2}$, AIDONG WEN ${ }^{2}$ and LEI SHI ${ }^{1}$ \\ ${ }^{1}$ Department of Pharmacy, General Hospital of Guangzhou Military Command of PLA, Guangzhou, Guangdong 510010; \\ ${ }^{2}$ Department of Pharmacy, Xijing Hospital, Fourth Military Medical University, Xi'an, Shaanxi 710032, P.R. China
}

Received August 10, 2015; Accepted May 19, 2016

DOI: $10.3892 /$ ijmm.2016.2616

\begin{abstract}
Renal ischemia-reperfusion (I/R) injury is associated with high morbidity and mortality as there is currently no available effective therapeutic strategy with which to treat this injury. Thus, the aim of this study was to investigate the potential protective effects of brazilin, a major active component of the Chinese medicine Caesalpinia sappan L., against renal I/R injury in vitro and in vivo. Rats were subjected to removal of the right kidney and I/R injury to the left kidney (ischemia for $45 \mathrm{~min}$ followed by reperfusion for $24 \mathrm{~h})$. Treatment with brazilin $(30 \mathrm{mg} / \mathrm{kg}$, administered intravenously at $30 \mathrm{~min}$ prior to ischemia) led to the reversal of I/R-induced changes in serum creatinine (Scr) and blood urea nitrogen (BUN) levels, and also attenuated the histopathological damage induced by I/R. Furthermore, TUNEL assay revealed that brazilin reduced cell necrosis, and significantly decreased the expression of tumor necrosis factor (TNF)- $\alpha$ and interleukin (IL)- $1 \beta$ in renal tissue. Moreover, HK-2 cells were used in order to elucidate the mechanisms responsible for the protective effects of brazilin. The levels of phosphorylated I $\mathrm{B} \alpha$ and the nuclear translocation of nuclear factor- $\kappa \mathrm{B}(\mathrm{NF}-\kappa \mathrm{B})$ were all evidently decreased by brazilin. These findings suggested that pre-treatment with brazilin protects against I/R-induced renal damage and suppresses the inflammatory response by inhibiting the activation of the NF- $\kappa \mathrm{B}$ signaling pathway.
\end{abstract}

Correspondence to: Professor Lei Shi, Department of Pharmacy, General Hospital of Guangzhou Military Command of PLA, 111 Liu Hua Road, Guangzhou, Guangdong 510010, P.R. China E-mail: xjyypharmacy@126.com

Professor Aidong Wen, Department of Pharmacy, Xijing Hospital, Fourth Military Medical University, 129 Changle Xi Road, Xi'an, Shanxi 710032, P.R. China

E-mail: aidongwen71@hotmail.com

${ }^{*}$ Contributed equally

Abbreviations: I/R, ischemia-reperfusion; Scr, serum creatinine; BUN, blood urea nitrogen; OGD, oxygen-glucose deprivation

Key words: brazilin, renal ischemia-reperfusion injury, nuclear factor- $\kappa \mathrm{B}$, anti-inflammatory, tumor necrosis factor- $\alpha$, interleukin- $1 \beta$

\section{Introduction}

Renal ischemia-reperfusion (I/R) injury is a major cause of acute kidney injury (AKI), and can occur in a number of clinical settings including shock, renal transplantation $(1,2)$, renal artery angioplasty and contrast agent-induced nephropathy (3-8). The prognosis for patients with $I / R$ injury is poor and currently there is no available effective therapy to counteract this injury. Thus, renal I/R injury is associated with high morbidity and mortality (9-12). Due to its complex pathogenesis, a vast body of evidence has suggested that inflammation plays a critical role in renal injury following I/R. Nuclear factor- $\kappa \mathrm{B}(\mathrm{NF}-\kappa \mathrm{B})$ is a pivotal pathway which activates the inflammatory response during renal I/R injury (13). Moreover, interleukin (IL)-1 $\beta$ and tumor necrosis factor (TNF)- $\alpha$ are the most critical cytokines involved in the inflammatory response in I/R injury (14-19). Pro-inflammatory cytokines (TNF- $\alpha$ and IL-1 $\beta$ ) activate the inflammatory reaction, resulting in inflammatory injury (16-19).

Brazilin, [7,11b-dihydrobenz(b)indeno [1,2-d]pyran-3,6a, 9,10(6H)-tetrol] (chemical structure shown in Fig. 1A), isolated from Caesalpinia sappan L., has been shown to have various biological activities, such as antioxidant and anti-inflammatory activities, and has been shown to regulate apoptosis and cell cycle arrest. Brazilin has been shown to protect rat hepatocytes from $\mathrm{BrCCl}_{3}$-induced toxicity (20), and to mediate the action of HO-1 (21) and the inducible nitric oxide synthase (iNOS) gene (22), inhibiting inflammatory injury. Moreover, brazilin has been shown to regulate apoptosis and cell cycle arrest by inhibiting the activity of histone deacetylases (HDACs) (23). It has also been reported that brazilin prevents various biological activities, such as platelet aggregation, inflammation, vasorelaxation and apoptosis, and inhibits vascular smooth muscle cell proliferation and migration induced through platelet-derived growth factor (PDGF)-BB (24). However, the mechanisms responsible for the protective effects of brazilin against renal injury remain unexplored.

In the present study, we aimed to investigate the potential therapeutic effects of brazilin on I/R-induced renal injury and to elucidate the underlying mechanisms. We aimed to determine whether brazilin plays a direct role in the protection against inflammatory renal injury induced by $\mathrm{I} / \mathrm{R}$, as well as whether the activation of the NF- $\kappa$ B pathway plays a pivotal role in the inflammatory response during renal I/R injury. 


\section{Materials and methods}

Materials. Brazilin (purity $>98.0 \%$ ) was purchased from the National Institute for the Control of Pharmaceutical and Biological Products (11181-201302; Beijing, China). HK-2 cells were obtained from the European Collection of Cell Cultures (Salisbury, UK). Dulbecco's modified Eagle's medium (DMEM) and other cell culture supplies were purchased from Gibco (Grand Island, NY, USA). 3-(4,5-Dimethylthiazol-2-yl)-2,5diphenyltetrazolium bromide (MTT) was obtained from Sigma Chemical Co. (St. Louis, MO, USA). Rabbit monoclonal antibodies to $\mathrm{NF}-\kappa \mathrm{B}$ (p65; 9460S), and rabbit polyclonal antibodies specific for $\beta$-actin (4970L) and proliferating cell nuclear antigen (PCNA; 8580S) and I $\mathrm{B} \alpha(4088 \mathrm{~S})$, were the products of Cell Signaling Technology, Inc. (Beverly, MA, USA). All materials for sodium dodecyl sulfate-polyacrylamide gel electrophoresis (SDS-PAGE) were obtained from Bio-Rad Laboratories, Inc. (Hercules, CA, USA).

Adult Sprague-Dawley rats (purchased from the Department of Laboratory Animal Science, Fourth Military Medical University, Xi'an, China), weighing 250-300 g, were used in the present study. All the animal welfare and experimental procedures were carried out strictly in accordance with the Guide for the Care and Use of Laboratory Animals (NIH publication no. 85-23, National Academy Press, Washington, DC, USA, revised 1996). The experimental procedures involving animals in this study were approved by the Animal Ethics Committee of Fourth Military Medical University. All experimental rats were kept in an environmentally controlled breeding room for 5 days before being used in the experiments and were fed with standard laboratory food and water.

Rat model of renal $I / R$ injury. Pathogen-free, male Sprague-Dawley rats were fasted overnight. The rat model of renal I/R injury and the surgical procedures involved wre similar to those previously described $(25,26)$. All rats were anesthetized with sodium chloral hydrate $(85 \mathrm{mg} / \mathrm{kg}$ intraperitoneally) (Rhone Merieux Limited, Essex, UK) and placed in a prone position on a warming pad at $37^{\circ} \mathrm{C}$ in order to perform the surgical procedures. The sham-operated rats (group 1) were only subjected to the removal of the right kidney, whereas the rats in groups 2 to 3 were also subjected to acute I/R injury to the left kidney which was induced by clamping the renal artery for 45 min using non-traumatic vascular clips. The clamp was then removed for reperfusion. Blood was collected from the eye socket at 4, 10 and $24 \mathrm{~h}$ after reperfusion and the left kidney was removed at $24 \mathrm{~h}$. The rats were sacrificed by decapitation and exsanguination at $24 \mathrm{~h}$ after the I/R procedure. The kidneys were harvested for analysis.

The rats were randomly and equally divided into 3 groups as follows: group $1(n=8)$, the right kidney was extirpated for the sham-operated animals, but neither clamping nor infusion in the left kidney were performed; group $2(n=8)$, the rats subjected to renal $\mathrm{I} / \mathrm{R}$ injury rats were treated with saline as the vehicle; group $3(n=8)$, the rats subjected to renal I/R injury were treated with brazilin $(30 \mathrm{mg} / \mathrm{kg}$, intravenous administration) $0.5 \mathrm{~h}$ prior to I/R injury.

Assessment of renal function before and after the I/R procedure. Blood was collected using retro-orbital puncture at 4,10 and $24 \mathrm{~h}$ following reperfusion. Serum was separated by centrifugation at $2,700 \times \mathrm{g}$ and at $4^{\circ} \mathrm{C}$, and serum creatinine (Scr) and blood urea nitrogen (BUN) levels were determined by staff at the Clinical Laboratory of Xijng Hospital, who were blinded to the treatments given. Blood samples were stored at $-80^{\circ} \mathrm{C}$ for analysis.

Histological evaluation. Staff at the pathology department of our hospital, who were blinded to the treatments given, performed the morphological assessment. Transverse slices of the left kidneys were fixed in $10 \%$ buffered formalin and embedded in paraffin. The kidney sections were stained with hematoxylin and eosin. One hundred intersections were examined for each kidney, and a score of 0 to 3 was given for each tubular profile. The scoring method has been described previously (27) and was as follows: 0 , normal histology; 1, tubular cell swelling, brush border loss, nuclear condensation, with up to one third of the tubular profile showing nuclear loss; 2 , as for score 1 but greater than one third and less than two thirds of the tubular profile showing nuclear loss; and 3, greater than two thirds of the tubular profile showing nuclear loss. The total score for each kidney was calculated by the addition of all 100 scores with a maximum score of 300 .

Determination of apoptosis. Renal cell apoptosis was detected by a terminal deoxynucleotidyltransferase-mediated dUTP nickend labelling (TUNEL) assay with tissue paraffin blocks. The renal slides were incubated with TUNEL reaction mixture in a humidified chamber for $60 \mathrm{~min}$ at $37^{\circ} \mathrm{C}$ in the dark. The renal sections were then rinsed in phosphate-buffered saline (PBS) 3 times, and the nuclei were mounted with 4',6-diamidino2-phenylindole (DAPI) at a concentration of $300 \mathrm{nM}$. Apoptosis was quantified by calculating the percentage of TUNEL-positive nuclei out of the total nuclei in an average of 20 high-power fields for each section in a blinded manner.

Immunofluorescence staining. Immunostaining of the frozen kidney sections from the rats was performed using rabbit polyclonal anti-IL-1 $\beta$ (ab9722) and anti-TNF- $\alpha$ (ab9755) antibodies (Abcam, Cambridge, UK). The primary antibody was detected using Alexa Fluor ${ }^{\circledR} 594$ donkey and anti-rabbit $\lg \mathrm{G}(\mathrm{H}+\mathrm{L})$ labeled secondary antibodies (Cat. no. 1256153; Life Technologies, Grand Island, NY, USA), and incubated for $120 \mathrm{~min}$ at room temperature in the dark. DAPI (SigmaAldrich) was used for nuclear staining. Images were captured using Nikon DS-Qi1Mc camera attached to Nikon Eclipse 90i fluorescence microscope using an oil immersion objective 60/1.4 NA by Nikon NIS elements AR version 3.2 software.

Oxygen-glucose deprivation (OGD) and determination of cell viability. The cells were cultured in DMEM/F12(1:1), and passaged every 2-3 days in 100-mm dishes supplemented with $10 \%$ fetal bovine serum, $2 \mathrm{mM}$ glutamine, $100 \mathrm{U} / \mathrm{ml}$ penicillin and $100 \mu \mathrm{g} / \mathrm{ml}$ streptomycin (Life Technologies). The cells were grown at $37^{\circ} \mathrm{C}$ in a humidified $5 \% \mathrm{CO}_{2}$ atmosphere. In order to mimic ischemia-like conditions in vitro, the HK-2 cells were exposed to ischemia by replacing the medium with an 'ischemic buffer' (5 mM HEPES, $137 \mathrm{mM} \mathrm{NaCl}$, $4 \mathrm{mM} \mathrm{KCl}, 1 \mathrm{mM} \mathrm{MgCl}_{2}$ and $1.5 \mathrm{mM} \mathrm{CaCl}_{2}, \mathrm{pH}$ 7.0). The cells were then incubated in the hypoxic/ischemic chamber (Billups-Rothenberg, Inc., Del Mar, CA, USA) at $37^{\circ} \mathrm{C}$ for $60 \mathrm{~min}$ in a humidified atmosphere of $5 \% \mathrm{CO}_{2}$ and $95 \% \mathrm{~N}_{2}$. 

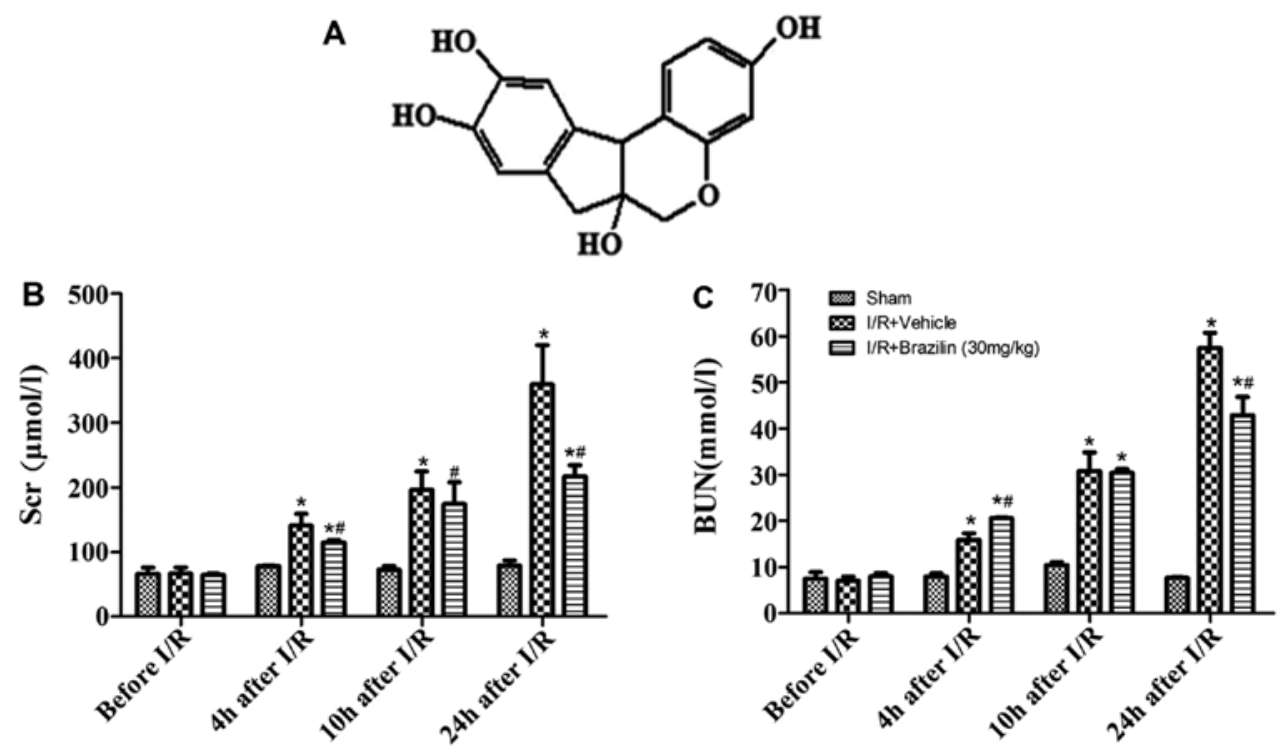

Figure 1. (A) Chemical structure of brazilin. (B and C) Pre-treatment with brazilin improves renal function after ischemia-reperfusion (I/R) injury. (B) The increase in the serum creatinine (Scr) levels at 4,10 and $24 \mathrm{~h}$ after I/R was abrogated by brazilin $(30 \mathrm{mg} / \mathrm{kg}$, administered intraperitoneally) (n=8 rats/group). (C) The increase in blood urea nitrogen (BUN) levels at 4, 10 and $24 \mathrm{~h}$ after reperfusion after $\mathrm{I} / \mathrm{R}$ was abrogated by brazilin ( $30 \mathrm{mg} / \mathrm{kg}$, administered intraperitoneally) ( $\mathrm{n}=8$ rats/group). ${ }^{*} \mathrm{P}<0.05$ vs. sham-operated (Sham) group; ${ }^{*} \mathrm{P}<0.05$ vs. $\mathrm{I} / \mathrm{R}+$ Vehicle group.

Finally, the cells were incubated again in the culture medium in an incubator with $95 \%$ air and $5 \% \mathrm{CO}_{2}$ for an additional $24 \mathrm{~h}$ as previously described (32-35). Prior to exposure to OGD, the HK-2 cells were incubated with brazilin $(0.5 \mathrm{mM})$ of the vehicle for $2 \mathrm{~h}$. OGD-induced cell death was quantified by MTT assay (Sigma-Aldrich).

Cell viability assay. Cell viability was measured using the EZ-Cytox Cell Viability Assay kit (MTT) assay (Itsbio, Seoul, Korea). MTT assay is based on the cleavage of the tetrazolium salt, MTT, to the water-insoluble formazan. The formazan dye produced by viable cells can be quantified by measuring the absorbance of the dye solution at $460 \mathrm{~nm}$. The HK-2 cells were seeded in 96 -well plates $\left(5 \times 10^{3}\right.$ cells/well $)$ at $37^{\circ} \mathrm{C}$ in a $5 \% \mathrm{CO}_{2}$ incubator in DMEM/F12. Following overnight incubation, the cells were incubated for $24 \mathrm{~h}$ in the presence or absence of brazilin $(0.2,0.5$ and $1.0 \mathrm{mM})$ for $2 \mathrm{~h}$ prior to exposure to OGD. The final incubation of the cells with $10 \mu \mathrm{l}$ of kit reagent was performed for $45 \mathrm{~min}$ at $37^{\circ} \mathrm{C}$. The absorbance was measured at $460 \mathrm{~nm}$ using a microplate reader (Bio-Rad Laboratories, Inc.). Cell viability was calculated and averaged. The cells from the control group were treated in the same manner without exposure to OGD, and cell viability was expressed as a percentage of the untreated controls.

Western blot analysis. The cells were washed with ice-cold PBS and lysed in ice-cold modified RIPA lysis buffer $(50 \mathrm{mM}$ Tris-HCl, pH 7.5, $150 \mathrm{mM} \mathrm{NaCl}, 50 \mathrm{mM} \mathrm{NaF}, 0.5 \%$ deoxycholic acid, 1\% NP-40, $1 \mathrm{mM}$ sodium orthovanadate and 0.1\% SDS). The insoluble material was then removed by centrifugation at $12,000 \mathrm{x} \mathrm{g}$ for $15 \mathrm{~min}$ at $4^{\circ} \mathrm{C}$. The protein concentration of each sample was measured using a Bio-Rad Protein Assay kit (Bio-Rad Laboratories, Inc.). Following quantification of thye protein concentration, the denatured protein was separated by SDS-PAGE and then transferred to polyvinylidene difluoride (PVDF) membranes. After being blocked with $5 \%(\mathrm{w} / \mathrm{v})$ non-fat milk at $37^{\circ} \mathrm{C}$ for $30 \mathrm{~min}$, the membranes were incubated overnight at $4^{\circ} \mathrm{C}$ with primary antibodies to NF- $\kappa \mathrm{B}(\mathrm{p} 65), \mathrm{I} \kappa \mathrm{B} \alpha$, $\beta$-actin and PCNA. Following 3 washes in TBS-T, the membranes were incubated for $30 \mathrm{~min}$ with a horseradish peroxidaseconjugated secondary antibody diluted in TBS-T. The blots were visualized using the enhanced chemiluminescence method, and the bands were scanned and quantified by densitometric analysis.

Statistical analyses. Data are expressed as the means \pm SD and using SPSS 14.0 for Windows (SPSS, Inc., Chicago, IL, USA). Histopathological scores were analyzed by Kruskal-Wallis nonparametric analysis of variance followed by Dunn's multiple comparison test. The remaining data were analyzed by one-way analysis of variance (ANOVA), followed by a least square difference (LSD) multiple comparison test. A P-value $<0.05$ was considered to indicate a statistically significant difference. All statistical analyses were performed using GraphPad Prism software version 5.02 (GraphPad Software, Inc., San Diego, CA, USA).

\section{Results}

Brazilin protects against renal $I / R$ injury. As shown in Fig. $1 \mathrm{~B}$ and $\mathrm{C}$, renal $\mathrm{I} / \mathrm{R}$ injury led to a significant increase in the levels of Scr and BUN in a time-dependent manner following reperfusion. Twenty-four hours after renal reperfusion, the rats subjected to $I / R$ and treated with the vehicle $(I / R+$ vehicle group) developed significant renal dysfunction indicated by an increase in Scr (359.25 \pm 60.69$)$ and BUN (57.47 \pm 3.26$)$ levels. The rats pre-treated with brazilin rats did not exhibit such a significant increase in Scr $(216.50 \pm 17.68)$ and BUN (42.91 \pm 3.96$)$ levels. The administration of brazilin resulted in a significant decrease in the Scr and BUN levels compared to the rats administered the vehicle (Fig. 1B and C).

Renal tubular damage in the rats in the $\mathrm{I} / \mathrm{R}+$ vehicle group was observed in the outer medulla, as evidenced by widespread 
A

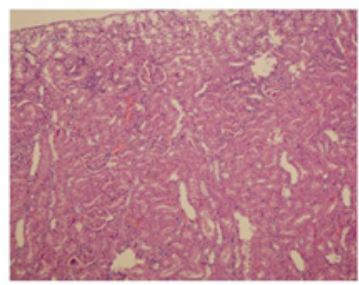

Sham

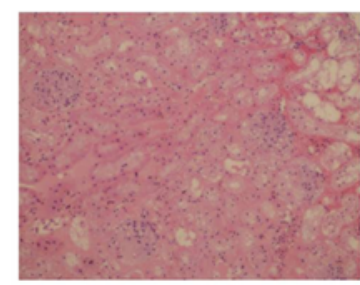

I/R+Vehicle

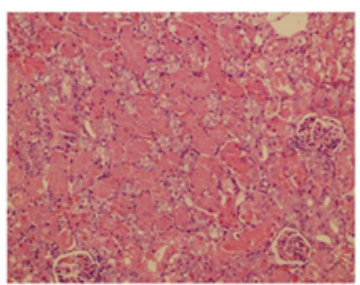

I/R+Brazilin
B

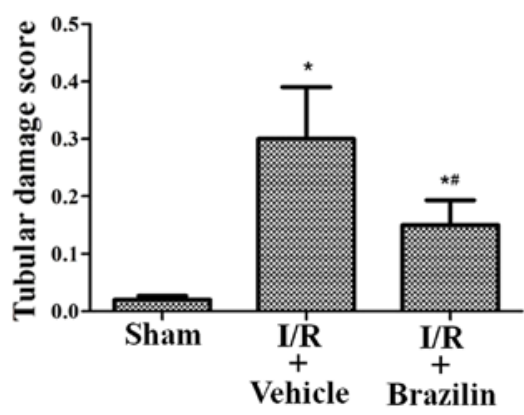

C

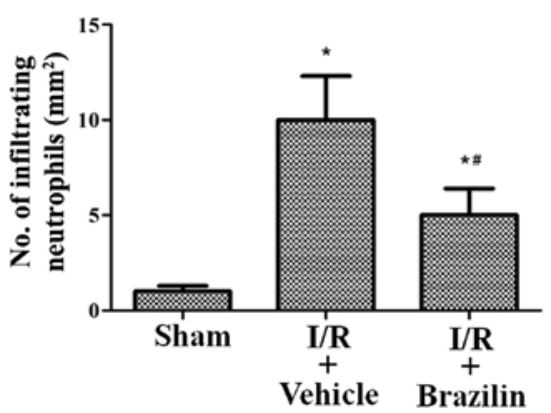

Figure 2. Pre-treatment with brazilin attenuates renal damage induced by ischemia-reperfusion (I/R). Representative photomicrographs (hematoxylin and eosin staining; magnification, x200) of renal sections from rats under various experimental conditions. (A) Renal histopathology. Hematoxylin and eosin-stained sections are from the outer medulla (representative images of at least 3 experiments). (B) Quantitative scores of tubular injury. The analysis was performed under the same magnification for the respective groups. (C) Neutrophil accumulation within the interstitium of the renal was significantly less in the I/R + Brazilin group versus the $\mathrm{I} / \mathrm{R}+$ Vehicle group at $24 \mathrm{~h}$ after reperfusion. ${ }^{*} \mathrm{P}<0.05$ vs. sham-operated (Sham) group; ${ }^{*} \mathrm{P}<0.05$ vs. I/R + Vehicle group.
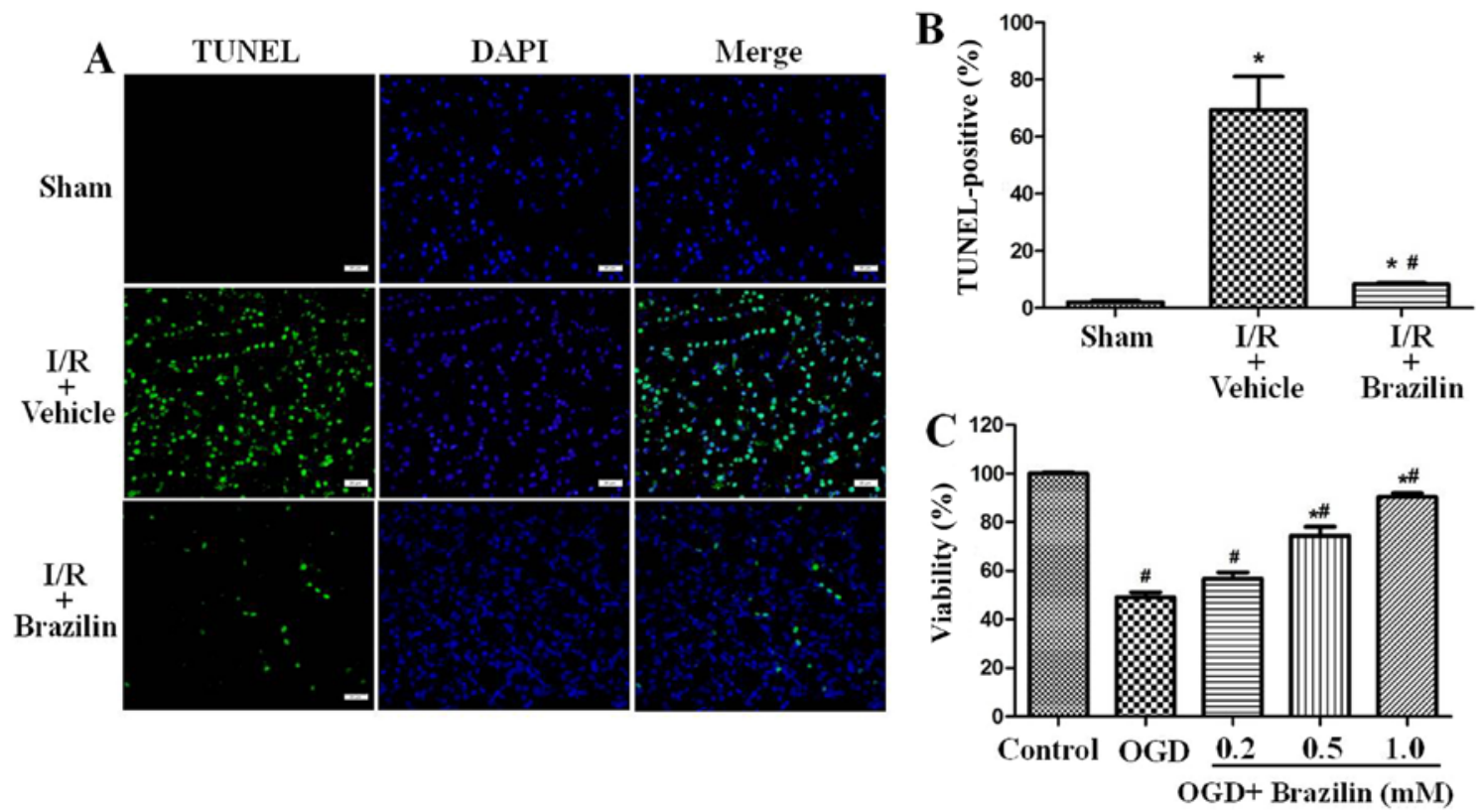

Figure 3. Brazilin preconditioning ameliorates tubular apoptosis induced by renal ischemia-reperfusion (I/R). (A) Representative images (magnification, $\mathrm{x} 400$ ) of renal TUNEL assay from rats subjected to sham-operation, renal I/R and brazilin + I/R. (B) The percentage of TUNEL-positive cells in the kidney sections increased following $\mathrm{I} / \mathrm{R}$ and decreased following treatment with brazilin $\left({ }^{*} \mathrm{P}<0.05\right.$ vs. sham-operated (sham) group and ${ }^{\#} \mathrm{P}<0.05$ vs. $\mathrm{I} / \mathrm{R}+\mathrm{Vehicle}$ group; $\mathrm{n}=8$ rats per group). (C) Protective effects of brazilin $(0.25,0.5$ and $1.0 \mathrm{mM})$ against the renal $\mathrm{I} / \mathrm{R}$-induced loss of cell viability. Cells in the control group (0 mM group or Control group) were considered $100 \%$ viable. Data are presented as the means $\pm \mathrm{SD}(\mathrm{n}=6) .{ }^{\sharp} \mathrm{P}<0.01$ vs. Control group, ${ }^{*} \mathrm{P}<0.01$ vs. I/R group.

tubular necrosis, luminal congestion and the significant infiltration of neutrophils at $24 \mathrm{~h}$ following reperfusion. However, pre-treatment with brazilin substantially reduced tubular damage (Fig. 2A). The rats pre-treated with brazilin exhibited a markedly lower renal tubular injury score and neutrophil infiltration (Fig. 2B and C). TUNEL staining of the renal sections was then performed to visualize DNA fragmentation in situ. In the I/R + vehicle group, TUNEL-positive cells were densely distributed. Pre-treatment with brazilin significantly reduced amount of TUNEL-positive cells (Fig. 3A). In the rats pre-treated with brazilin, the percentage of TUNEL-positive cells in the renal sections decreased from $69.40 \pm 11.74$ to $8.25 \pm 0.52 \%$ (Fig. 3B). 


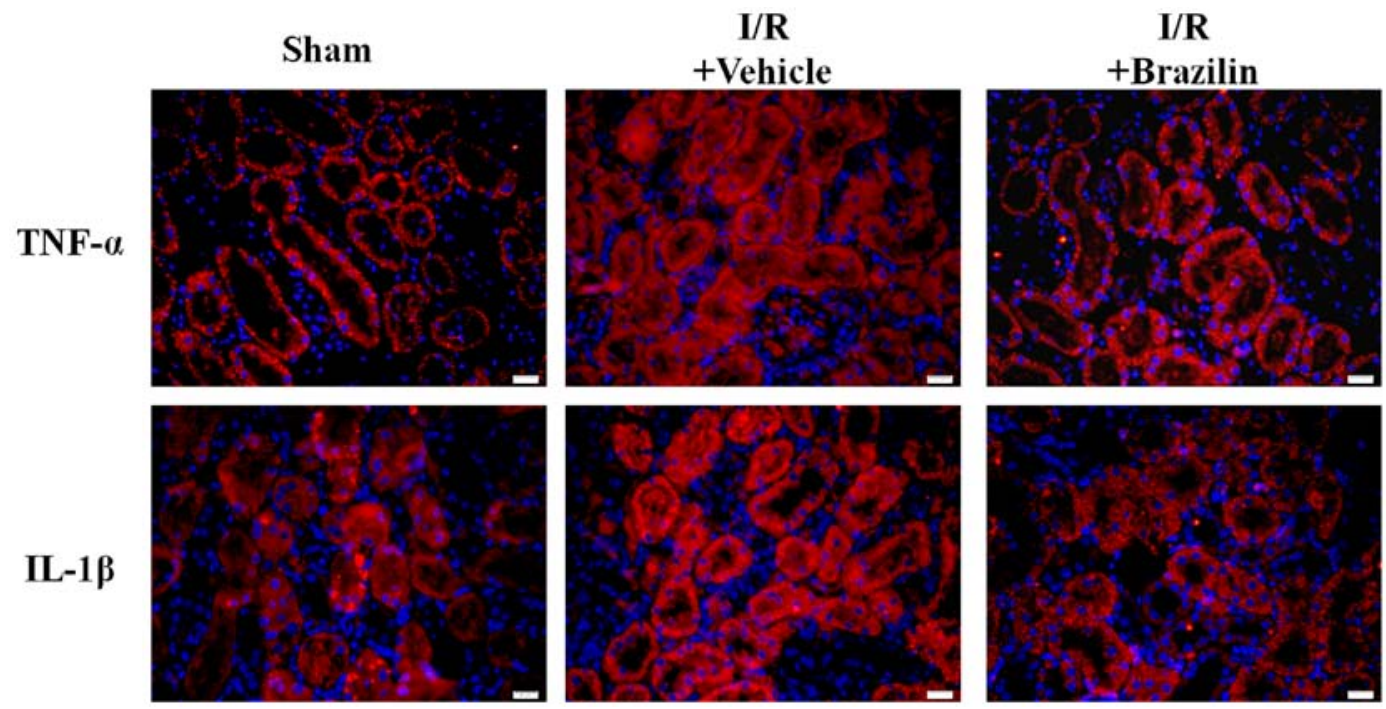

Figure 4. Pre-treatment with brazilin attenuates renal inflammatory injury induced by ischemia-reperfusion (I/R). Representative images (magnification, $\mathrm{x} 400)$ of renal immunofluorescence staining of renal sections from rats subjected to sham-operation, renal I/R or brazilin $+\mathrm{I} / \mathrm{R}$. $\mathrm{n}=8$ rats/group.

A

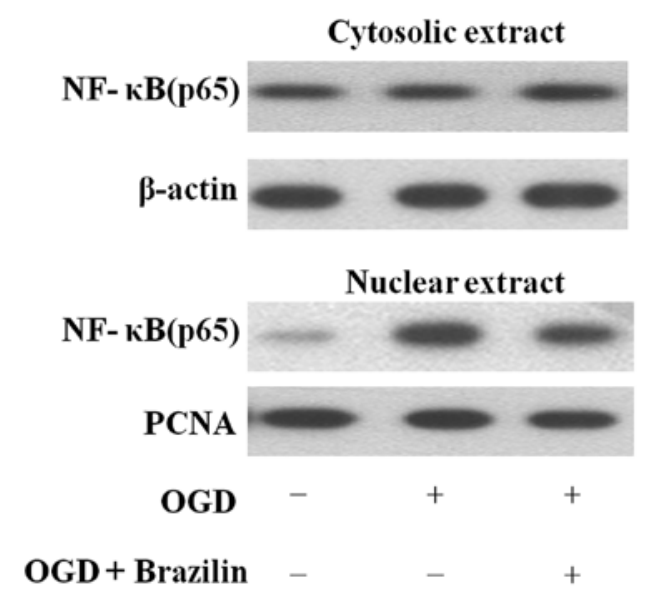

B
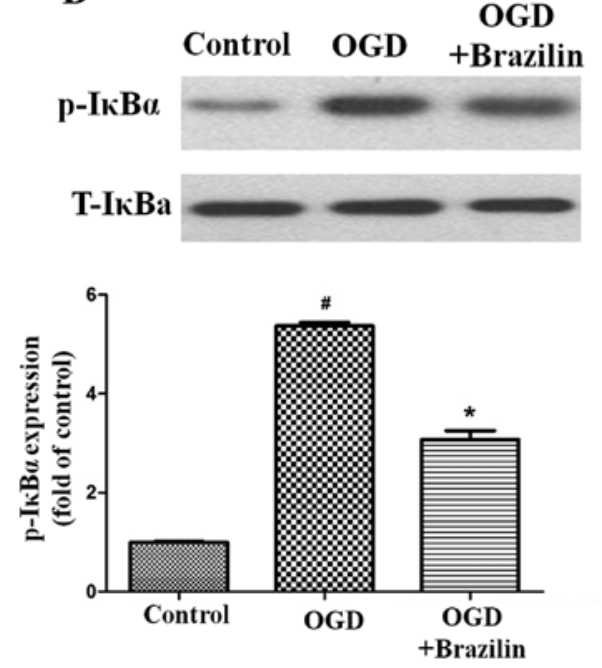

Figure 5. Effects of brazilin on the activation of the NF- $\mathrm{B}$ pathway in HK-2 cells subjected to renal ischemia-reperfusion (I/R). (A) Effects of brazilin on the renal I/R-induced nuclear translocation of NF- $\mathrm{BB}$. The changes in the expression of NF- $\kappa \mathrm{B}$ in cytosolic and nuclear extracts were examined by western blot analysis. The levels of NF- $\kappa \mathrm{B}$ in nuclear fractions and $\mathrm{I} \kappa \mathrm{B} \alpha$ in cytosolic fractions were examined by western blot analysis and corrected by PCNA and $\beta$-actin respectively. (B) Effects of brazilin on I/R-induced I $\mathrm{B} \alpha$ phosphorylation. $\mathrm{p}$-I $\mathrm{B} \mathrm{B} \alpha$ levels were also measured by western blot analysis and normalized to $\beta$-actin and presented as a fold of the control. Data are presented as the means \pm SD of 3 independent experiments. ${ }^{\#} \mathrm{P}<0.01$ vs. Control group, ${ }^{*} \mathrm{P}<0.01 \mathrm{vs}$. I/R group [exposed to oxygen-glucose deprivation (OGD)].

HK-2 cells were also pre-treated with brazilin for $2 \mathrm{~h}$, and were then exposed to OGD for $60 \mathrm{~min}$ in order to mimic ischemic-like conditions in vitro. The cells were then incubated again in an incubator with $95 \%$ air and $5 \% \mathrm{CO}_{2}$ with the vehicle or brazilin for an additional $24 \mathrm{~h}$. Exposure to OGD resulted in $49.07 \pm 2.61$ cell death. However, cell viability was significantly increased to $90.31 \pm 1.64 \%$ in the cells pre-treated with brazilin (1 mM) (Fig. 3C).

Brazilin supression the inflammatory response by inhibiting the activation of $N F-\kappa B$. Immunofluorescence staining was performed on histological sections in order to examine the expression of inflammatory cytokines. The results revealed that the expression of TNF- $\alpha$ and IL-1 $\beta$ was enhanced in the
$\mathrm{I} / \mathrm{R}+$ vehicle group. However, in the renal sections from the rats pre-treated with brazilin ( $/ \mathrm{R}+$ Brazilin group), we observed a marked inhibition of TNF- $\alpha$ and IL-1 $\beta$ expression (Fig. 4).

In order to confirm the NF- $\kappa \mathrm{B}$ inhibitory activity of brazilin, we examined the nuclear translocation of the NF- $\kappa \mathrm{B}$ p65 subunit in the HK-2 cells. Pre-treatment with brazilin effectively inhibited the OGD-mediated nuclear translocation of p65 (Fig. 5A). We then examined the phosphorylation of $\mathrm{I} \kappa \mathrm{B} \alpha$. Upon exposure to OGD, the phosphorylation of $\mathrm{I} \kappa \mathrm{B} \alpha$ was increased (Fig. 5B). Pre-treatment of the cells with brazilin significantly inhibited the phosphorylation of $\mathrm{I} \kappa \mathrm{B} \alpha$. Taken together, the present data demonstrate that brazilin suppresses inflammation by inhibiting the activation of $\mathrm{NF}-\kappa \mathrm{B}$ following exposure to OGD. 


\section{Discussion}

Previous studies have demonstrated that brazilin protects against hepatic and brain injury $(20,28,30)$ as an antioxidant. However, the mechanisms responsible for the protective effects of brazilin against renal injury remain unexplored. In the present study, we firstly demonstrated that brazilin protected the rats against renal I/R injury by improving morphology, reducing the levels of inflammatory markers and preventing apoptosis. It also prevented the activation of $\mathrm{NF}-\kappa \mathrm{B}$. Thus, brazilin exerted anti-inflammatory effects both in vitro and in vivo.

As already mentioned, renal I/R injury is associated with high morbidity and mortality, due to the fact that patients with $\mathrm{I} / \mathrm{R}$ injury have a poor poor prognosis and there is currently no effective available therapy to counteract this injury (9-12). Thus, prevention may be strategy with which to improve the survival following I/R injury and AKI. In this study, pre-treatment with brazilin ameliorated renal function by decreasing the levels of Scr and BUN, and reducing the apoptosis of renal cells. Indeed, the pathogenesis of I/R injury involves a complex interplay between biochemical, cellular, vascular endothelial and tissue-specific factors.

Inflammation is one of the major factors contributing to renal damage following I/R (29). A number of inflammatory mediators are involved in renal $\mathrm{I} / \mathrm{R}$ damage. Of these mediators, TNF- $\alpha$ and IL- $1 \beta$ are the essential ones, and interact with each other. TNF- $\alpha$ is invovled in the initial phase of the inflammatory response induced by $\mathrm{I} / \mathrm{R}$ (14). It is capable of inducing the expression of different types of pro-inflammatory mediators, such as IL-1 $\beta$ (14-19). In this study, we demonstrated that pre-treatment with brazilin represents a feasable method with which to reduce inflammation-related injury, as it decreased the levels IL-1 $\beta$ and TNF- $\alpha$ in renal tissue.

In this study, the protective and anti-inflammatory effects of brazilin on renal were examined. Furthermore, we performed experiments in order to elucidate the possible mechanisms involved. NF- $\kappa \mathrm{B}$ is an ubiquitously expressed transcription factor (13) and plays a significant role in the inflammatory response (15). Our study focused on the $N F-\kappa B$ signaling pathway. As is known, in its inhibited form, the NF- $\kappa$ B dimer is segregated in the cytoplasm bound to an inhibitory protein known as I $\mathrm{B}$. The inhibition of $\mathrm{NF}-\kappa \mathrm{B}$ is inactivated by various stimuli including $\mathrm{I} / \mathrm{R}$, which firstly results in the phosphorylation of $\mathrm{I} \kappa \mathrm{B}$ and its subsequent degradation via proteosomes. Subsequently, $\mathrm{NF}-\kappa \mathrm{B}$ is released and translocates to the nucleus and binds to the promoter or enhancer of specific genes, leading to the activation of those encoding cytokines, and intercellular adhesion molecules (31). Thus, it can be perceived that a curb on the NF- $\mathrm{BB}$ signaling pathway is bound to be implicated in the regulation of $\mathrm{I} / \mathrm{R}$-induced inflammatory reactions. In the present study, we demonstrated that the transcription factor $\mathrm{NF}-\kappa \mathrm{B}$ was closely involved in inflammation-related injury. This was manifested by the increased nuclear translocation of $\mathrm{NF}-\kappa \mathrm{B}$, and the enhanced phosphorylation or degradation of $\mathrm{I} \kappa \mathrm{B} \alpha$. Taken together, our data suggest that brazilin exerts a protective effect against renal I/R injury, and that these effects are mediated by the inactivation of inflammatory factors. Brazilin inhibited both the nuclear translocation of $N F-\kappa B$, and the phosphorylation or degradation of $\mathrm{I} \kappa \mathrm{B} \alpha$. These results indicate that the protective and anti-inflammatory effects of brazilin against renal I/R injury are dependent on the inhibition of the NF- $\kappa \mathrm{B}$ signaling pathway.

In conclusion, we have demonstrated that pre-treatment with brazilin at a clinically relevant concentration $(30 \mathrm{mg} / \mathrm{kg})$ reduces the degree of renal I/R injury, preventing further renal damage. The protective effects of brazilin may be mediated by its anti-inflammatory activities. The protective and antiinflammatory effects of brazilin against renal I/R injury are dependent on the inhibition of the NF- $\kappa \mathrm{B}$ signaling pathway. The results of this study indicate that brazilin has potential for use as a drug for the prevention of renal I/R injury and to improve the outcome of patients with delayed graft function following kidney transplantation, acute renal failure after major surgery and trauma, or septic shock.

\section{Acknowledgements}

This study was supported by grants from the National Natural Science Foundation of China (nos. 81201985 and 21372259), the National Administration of Chinese Traditional Medicine of Shannxi province (no. 113-JC047) and the China Postdoctoral Science Foundation Grant (no. 2014M552706).

\section{References}

1. Jang HR, Ko GJ, Wasowska BA and Rabb H: The interaction between ischemia-reperfusion and immune responses in the kidney. J Mol Med Berl 87: 859-864, 2009.

2. Sementilli A and Franco M: Renal acute cellular rejection: correlation between the immunophenotype and cytokine expression of the inflammatory cells in acute glomerulitis, arterial intimitis, and tubulointerstitial nephritis. Transplant Proc 42: 1671-1676, 2010.

3. Bagshaw SM, Bennett M, Haase M, Haase-Fielitz A, Egi M, Morimatsu H, D'amico G, Goldsmith D, Devarajan P and Bellomo R: Plasma and urine neutrophil gelatinase-associated lipocalin in septic versus non-septic acute kidney injury in critical illness. Intensive Care Med 36: 452-461, 2010.

4. Friedericksen DV, Van der Merwe L, Hattingh TL, Nel DG and Moosa MR: Acute renal failure in the medical ICU still predictive of high mortality. S Afr Med J 99: 873-875, 2009.

5. Parikh CR, Coca SG, Wang Y, Masoudi FA and Krumholz HM: Long-term prognosis of acute kidney injury after acute myocardial infarction. Arch Intern Med 168: 987-995, 2008.

6. Mansano AM, Vianna PT, Fabris VE, Silva LM, Braz LG and Castiglia YM: Prevention of renal ischemia/reperfusion injury in rats using acetylcysteine after anesthesia with isoflurane. Acta Cir Bras 27: 340-345, 2012.

7. Morgan CJ, Gill PJ, Lam S and Joffe AR: Peri-operative interventions, but not inflammatory mediators, increase risk of acute kidney injury after cardiac surgery: a prospective cohort study. Intensive Care Med 39: 934-941, 2013.

8. Shimizu S, Saito M, Kinoshita Y, Ohmasa F, Dimitriadis F, Shomori K, Hayashi A and Satoh K: Nicorandil ameliorates ischaemia-reperfusion injury in the rat kidney. Br J Pharmacol 163: 272-282, 2011.

9. Alsabbagh MM, Asmar A, Ejaz NI, Aiyer RK, Kambhampati G and Ejaz AA: Update on clinical trials for the prevention of acute kidney injury in patients undergoing cardiac surgery. Am J Surg 206: 86-95, 2013.

10. Di Nardo M, Ficarella A, Ricci Z, Luciano R, Stoppa F, Picardo S, Picca S, Muraca M and Cogo P: Impact of severe sepsis on serum and urinary biomarkers of acute kidney injury in critically ill children: An observational study. Blood Purif 35: 172-176, 2013.

11. Levy EM, Viscoli CM and Horwitz RI: The effect of acute renal failure on mortality. A cohort analysis. JAMA 275: 1489-1494, 1996.

12. Santos WJ, Zanetta DM, Pires AC, Lobo SM, Lima EQ and Burdmann EA: Patients with ischaemic, mixed and nephrotoxic acute tubular necrosis in the intensive care unit - a homogeneous population? Crit Care 10: R68, 2006. 
13. Frantz S, Tillmanns J, Kuhlencordt PJ, Schmidt I, Adamek A, Dienesch C, Thum T, Gerondakis S, Ertl G and Bauersachs J: Tissue-specific effects of the nuclear factor kappaB subunit p50 on myocardial ischemia-reperfusion injury. Am J Pathol 171: 507-512, 2007.

14. Majid DS: Tumor necrosis factor- $\alpha$ and kidney function: Experimental findings in mice. Adv Exp Med Biol 691: 471-480, 2011.

15. Shahid M, Francis J, Matrougui K and Majid DS: Involvement of tumor necrosis factor-alpha in natriuretic response to systemic infusion of nitric oxide synthase inhibitor in anesthetized mice. Am J Physiol Renal Physiol 299: F217-F224, 2010.

16. Wang P, Wu P, Siegel MI, Egan RW and Billah MM: Interleukin (IL)-10 inhibits nuclear factor kappa B (NF kappa B) activation in human monocytes. IL-10 and IL-4 suppress cytokine synthesis by different mechanisms. J Biol Chem 270: 9558-9563, 1995.

17. Bean AG, Freiberg RA, Andrade S, Menon S and Zlotnik A: Interleukin 10 protects mice against staphylococcal enterotoxin B-induced lethal shock. Infect Immun 61: 4937-4939, 1993.

18. Gérard C, Bruyns C, Marchant A, Abramowicz D, Vandenabeele P, Delvaux A, Fiers W, Goldman M and Velu T: Interleukin 10 reduces the release of tumor necrosis factor and prevents lethality in experimental endotoxemia. J Exp Med 177: 547-550, 1993.

19. Fiorentino DF,Zlotnik A, Mosmann TR, Howard M and O'Garra A: IL-10 inhibits cytokine production by activated macrophages. J Immunol 147: 3815-3822, 1991.

20. Moon CK, Park KS, Kim SG, Won HS and Chung JH: Brazilin protects cultured rat hepatocytes from $\mathrm{BrCCl} 3$-induced toxicity. Drug Chem Toxicol 15: 81-91, 1992.

21. Hu CM, Liu YH, Cheah KP, Li JS, Lam CS, Yu WY and Choy CS: Heme oxygenase-1 mediates the inhibitory actions of brazilin in RAW264.7 macrophages stimulated with lipopolysaccharide. J Ethnopharmacol 121: 79-85, 2009.

22. Bae IK, Min HY, Han AR, Seo EK and Lee SK: Suppression of lipopolysaccharide-induced expression of inducible nitric oxide synthase by brazilin in RAW 264.7 macrophage cells. Eur J Pharmacol 513: 237-242, 2005.

23. Kim B: Kim SH, Jeong SJ, Sohn EJ, Jung JH, Lee MH and Kim SH: Brazilin induces apoptosis and G2/M arrest via inactivation of histone deacetylase in multiple myeloma U266 cells. J Agric Food Chem 60: 9882-9889, 2012.

24. Guo J, Li L, Wu YJ, Yan Y, Xu XN, Wang SB, Yuan TY, Fang LH and Du GH: Inhibitory effects of Brazilin on the vascular smooth muscle cell proliferation and migration induced by PDGF-BB. Am J Chin Med 41: 1283-1296, 2013.
25. Chatterjee PK, Patel NS, Kvale EO, Cuzzocrea S, Brown PA, Stewart KN, Mota-Filipe H and Thiemermann C: Inhibition of inducible nitric oxide synthase reduces renal ischemia/reperfusion injury. Kidney Int 61: 862-871, 2002.

26. Chatterjee PK, Zacharowski K, Cuzzocrea S, Otto M and Thiemermann C: Inhibitors of poly (ADP-ribose) synthetase reduce renal ischemia-reperfusion injury in the anesthetized rat in vivo. FASEB J 14: 641-651, 2000.

27. Sharples EJ, Patel N, Brown P, Stewart K, Mota-Philipe H, Sheaff M, Kieswich J, Allen D, Harwood S, Raftery M, et al: Erythropoietin protects the kidney against the injury and dysfunction caused by ischemia-reperfusion. J Am Soc Nephrol 15: 2115-2124, 2004

28. Shen J, Zhang HY, Lin H, Su H, Xing DM and Du LJ: Brazilein protects the brain against focal cerebral ischemia reperfusion injury correlating to inflammatory response suppression. Eur J Pharmacol 558: 88-95, 2007.

29. Bonventre JV and Weinberg JM: Recent advances in the pathophysiology of ischemic acute renal failure. J Am Soc Nephrol 14: 2199-2210, 2003

30. Wang LT, Chen BL, Wu CT, Huang KH, Chiang CK and Hwa Liu S: Protective role of AMP-activated protein kinase-evoked autophagy on an in vitro model of ischemia/reperfusion-induced renal tubular cell injury. PLoS One 8: e79814, 2013.

31. Nichols TC: NF-kappaB and reperfusion injury. Drug News Perspect 17: 99-104, 2004.

32. Lee HT, Kim M, Kim M, Kim N, Billings FT IV, D'Agati VD and Emala CW Sr: Isoflurane protects against renal ischemia and reperfusion injury and modulates leukocyte infiltration in mice. Am J Physiol Renal Physiol 293: F713-F722, 2007.

33. Kumar S, Allen DA, Kieswich JE, Patel NS, Harwood S, Mazzon E, Cuzzocrea S, Raftery MJ, Thiemermann C and Yaqoob MM: Dexamethasone ameliorates renal ischemia-reperfusion injury. J Am Soc Nephrol 20: 2412-2425, 2009.

34. Lee HT and Emala CW: Preconditioning and adenosine protect human proximal tubule cells in an in vitro model of ischemic injury. J Am Soc Nephrol 13: 2753-2761, 2002.

35. Xie J and Guo Q: Apoptosis antagonizing transcription factor protects renal tubule cells against oxidative damage and apoptosis induced by ischemia-reperfusion. J Am Soc Nephrol 17: 3336-3346, 2006. 